Aus der Pferdeklinik der Vetsuisse-Fakultät Universität Zürich

(Direktor: Prof.Dr.med.vet. J. A. Auer)

\title{
Computer-Assisted Surgery for Screw Insertion into the Distal Sesamoid Bone in Horses: An In Vitro Study
}

\author{
INAUGURAL-DISSERTATION \\ zur Erlangung der Doktorwürde \\ der Vetsuisse-Fakultät \\ Universität Zürich
}

\author{
vorgelegt von \\ Diego Gygax \\ Tierarzt \\ aus Uerkheim \\ (Schweiz)
}

\author{
Genehmigt im Auftrag von \\ Prof. Dr. med. vet. Jörg A. Auer, Referent \\ Prof. Dr. med. vet. Christoph Lischer, Korreferent
}

Zürich 2006 


\title{
Computer-Assisted Surgery for Screw Insertion into the Distal Sesamoid Bone in Horses: An In Vitro Study
}

\author{
DIEGO GYGAX, MedVet, CHRISTOPH LISCHER, DrMedVet, Diplomate ECVS, Dagmar Nitzl, DrMedVet Melanie Rossol, MedVet, \\ and JOERG A. AUER, DrMedVet, MS, Diplomate ACVS \& ECVS
}

\begin{abstract}
Objective-To compare the precision of computer-assisted surgery with a conventional technique (CV) using a special guiding device for screw insertion into the distal sesamoid bone in horses.

Study Design-In vitro experimental study.

Sample Population-Cadaveric forelimb specimens.

Methods-Insertion of a $3.5 \mathrm{~mm}$ cortex screw in lag fashion along the longitudinal axis of intact (non-fractured) distal sesamoid bones was evaluated in 2 groups (8 limbs each): CV and computer-assisted surgery (CAS). For CV, the screw was inserted using a special guiding device and fluoroscopy, whereas for CAS, the screw was inserted using computer-assisted navigation. The accuracy of screw placement was verified by radiography, computed tomography, and specimen dissection.

Results-Surgical precision was better in CAS compared with CV.

Conclusion-CAS improves the accuracy of lateromedial screw insertion, in lag fashion, into the distal sesamoid bone.

Clinical Relevance-The CAS technique should be considered for improved accuracy of screw insertion in fractures of the distal sesamoid bone.

(C) Copyright 2006 by The American College of Veterinary Surgeons
\end{abstract}

\section{INTRODUCTION}

$\mathrm{F}$ RACTURE OF the distal sesamoid (navicular) bone is a rare cause of lameness, is very difficult to treat, and has a guarded prognosis for soundness. ${ }^{1}$ These fractures occur more commonly in the forelimb, with racing breeds having a higher incidence than pleasure horses. ${ }^{2}$ Three fracture types occur: simple (sagittal or oblique) fractures, avulsion or chip fractures, and multifragment fractures. ${ }^{3}$ Most simple fractures occur in a parasagittal plane, slightly medial or lateral to the midline, and are slightly separated but not displaced.

Fractures of the distal sesamoid bone heal slowly. Increased fracture gap occurred for up to 4 months after injury in 17 horses with complete distal sesamoid bone fractures. ${ }^{4}$ Failure of bony union may be caused by constant motion at the fracture site with a combination of tensile and loading forces resulting in fragment distraction. Synovial fluid from the distal interphalangeal joint or the navicular bursa may also inhibit healing. ${ }^{5}$

Nonsurgical management of complete fractures includes rest and heel elevation by use of a wedge-shaped shoe to reduce loading forces on the fractured bone. Palmar digital neurectomy may be necessary to alleviate lameness. ${ }^{4}$ Prognosis for soundness is improved after surgical reduction and internal fixation using interfragmentary compression to encourage bony union. ${ }^{3,4}$ Typically, a $3.5 \mathrm{~mm}$ cortical bone screw inserted in lag fashion provides adequate compression; however, precise screw insertion is critical to avoid penetration of the distal articular surface or the flexor surface. Thus, accurate radiographic monitoring, or preferably fluoroscopy, is needed during surgery. Special guides ${ }^{6}$ (Fig 1$)^{7}$ have been developed to improve the accuracy of screw insertion along the

From the Equine Hospital, University of Zürich, Zürich, Switzerland.

Address reprint request to Diego Gygax, MedVet, Winterthurerstrasse 260, 8057 Zürich, Switzerland. E-mail: dgygax@vetclinics. unizh.ch.

Submitted February 2006; Accepted June 2006

(c) Copyright 2006 by The American College of Veterinary Surgeons

0161-3499/06

doi:10.1111/j.1532-950X.2006.00200.x 


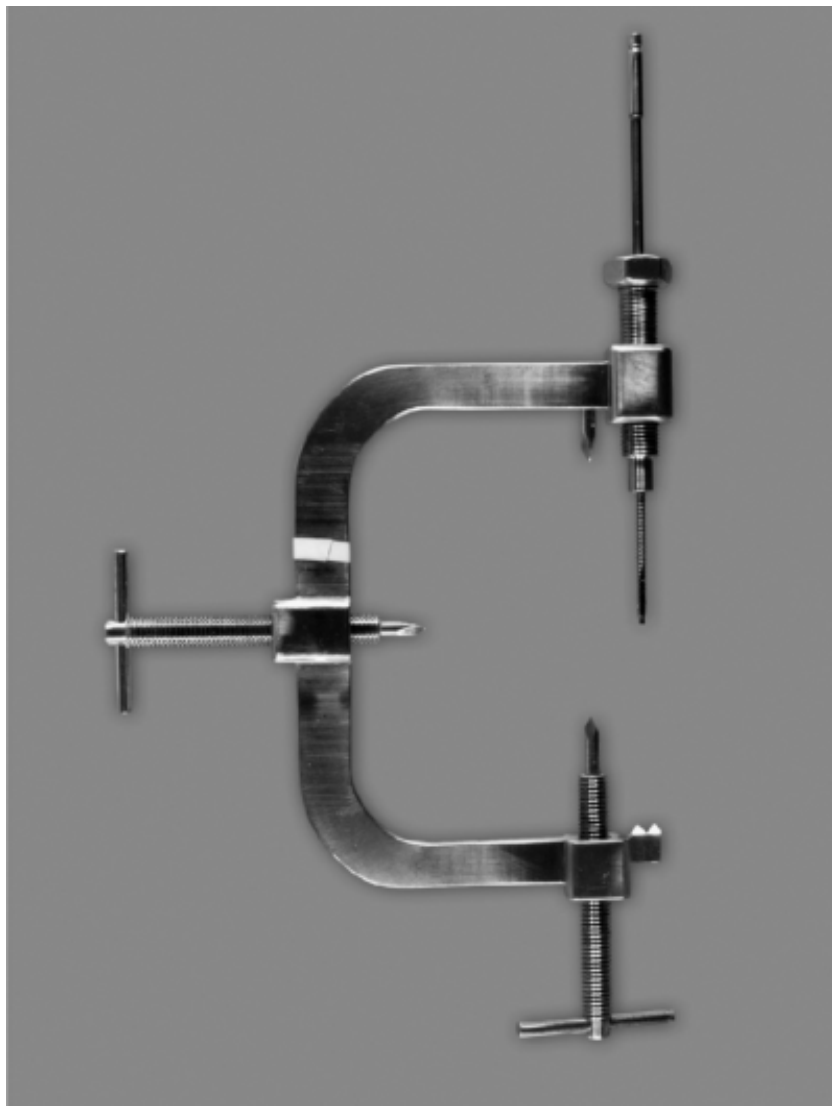

Fig 1. Guiding device for conventional inserting of a 3.5-mm screw into the distal sesamoid bone. The insert sleeve contains the 3.5-mm tap.

center of the transverse axis of the distal sesamoid bone. Use of imaging techniques to ensure accurate implant alignment is time consuming and increases radiation exposure of operating room personnel.

Computer-assisted surgery (CAS) has been used in human surgery to improve precision in procedures involving the spine, ${ }^{8}$ pelvis, ${ }^{9}$ and head. ${ }^{10}$ Its use and precision for transverse screw insertion in the distal phalanx of cadaveric equine limbs has been reported. ${ }^{11}$ Based on this experience and because of the difficulty in achieving accurate medial to lateral screw alignment in the distal sesamoid bone using other techniques, we evaluated the use of CAS to insert accurately a cortex screw transversely, and in lag fashion, in cadaveric equine limb specimens. We compared the accuracy of screw placement with outcome in other limb specimens where screw insertion was achieved using a guide. ${ }^{7}$ Because of the sophistication of the positioning system, we hypothesized that the CAS technique would result in greater accuracy of screw placement within the distal sesamoid bone. We evaluated the accuracy of screw position by imaging techniques and by examination of the distal sesamoid bone after dissection.

\section{MATERIALS AND METHODS}

\section{Cadaveric Limbs}

Eight limb pairs, disarticulated at the carpometacarpal joint, were collected from horses (different breeds and ages) that were euthanatized for reasons unrelated to pathology of the digits. The flexor tendons and the suspensory ligament were securely fixed to the third metacarpal bone (MC3) with a circumferential wire band at the midcarpal region. A radiolucent cord incorporated within the wire loop, on the dorsal surface of MC3, was threaded through 2 holes made in the dorsal solar rim of the hoof wall and then tightened to fix toe position in extension. This tightened the deep digital flexor tendon and limited motion of the distal sesamoid bone. Three, 2-mm-diameter lead beads used as surgical landmarks were inserted into shallow drill holes of the same diameter made in the lateral hoof wall and secured with cyanoacrylate glue.

The limbs were divided into 2 groups: 8 left limbs were used for a conventional screw insertion technique (CV) using a guide and fluoroscopy, whereas the 8 right limbs had screw insertion using CAS. CV was performed by one author (C.L.) and CAS by another (J.A.).

\section{Technical Equipment}

CAS. Images of the distal sesamoid bone were acquired with an isocentric C-arm fluoroscope (Siremobil Iso $\mathrm{C}^{3 \mathrm{~d}}$, Siemens Medical Solutions, Erlangen, Germany). This 3-dimensional (3D) imaging system allows collection of the images immediately before surgery obviating the need for a preoperative computed tomography (CT) scan. Over an arc of $190^{\circ}$, the $\mathrm{C}$-arm takes 100 sequential radiographs within a 2-minute time span. The images are then processed by the $\mathrm{C}$-arm computer to create a cube of a $12.5 \mathrm{~cm}$ side length consisting of individual 256 slices, followed by the coaxial transfer of images to the navigation computer (Sun Microsystems Inc., Mountain View, CA). The instruments are tracked with an active optoelectronic system (Medivision, Oberdorf, Switzerland). The power drill and a pointed awl are equipped with active markers consisting of infrared light-emitting diodes (LED). A dynamic reference base (DRB), which is applied to the target bone or hoof, and a virtual keyboard contain the same LEDs. The LEDs are also attached to a cylindrically shaped "marker carrier," which is attached over the barrel of the C-arm.

An optoelectronic infrared camera (Optotrak TM 3020, Northern Digital Inc., Waterloo, ON, Canada) is used for navigational purposes. It consists of 3 infrared sensors in line, allowing 3D localization of the marked instruments and objects. The information acquired by the camera is automatically transferred to the navigation computer, which projects the location and orientation of the instruments onto 3 different planes (horizontal, sagittal, transverse frontal) of the previously acquired radiographs. Together, these components work like a global positioning system (GPS). By means of the DRB, the system is capable of linking the real anatomy of the patient to the virtual reality on the computer screen.

The system software SurgiGATE 1.0 (Praxim-Medivision, Grenoble, France) offers different modes of operation. In the 
Planning Mode, the surgeon can navigate through the bone in all 3 planes to find the best possible position for screw placement. Screw position can be drawn onto the images and is represented by a red line of identical diameter as the screw. Screw length is automatically calculated and displayed on the screen. The alignment mode allows precise alignment of the instruments and the $\mathrm{C}$-arm for control radiographs. In verification mode, it is possible to check the accuracy of registration by matching the virtual and actual situation. By pointing an LED equipped and calibrated instrument at one or several clearly defined anatomic landmarks, the surgeon can check whether the registration process is accurate. The computer will display the possible inaccuracy of registration, depending on the distance between the camera and the DRB and on how clearly the camera can locate the DRB.

The guidance mode represents the actual navigation mode. It shows the position of the instrument used (green line), the alignment of its axis (yellow dotted line) in relation to patient anatomy as well as the planned screw (red line) simultaneously in all 3 orthogonal planes calculated by the C-arm computer. Information on the dorso-palmar/plantar and proximodistal location and alignment of the instrument is obtained in "real time," allowing immediate correction of the drill bit alignment during drilling. On an additional view, the axial trajectory is represented by 3 rings in different colors. The red ring represents the planned screw, the slightly larger green ring the tip, and the largest yellow ring the end of the instrument in use. The real-time mode follows the progress of all steps of screw insertion.

Except for the planning, which has to be performed with the help of a mouse, the navigation system can be operated with a conventional computer mouse by an assistant or by the surgeon with the help of a virtual keyboard and a foot pedal. The foot pedal substitutes the left mouse key, while the virtual keyboard allows switching between the different modes without jeopardizing sterility. The keyboard is also used for calibrating the length of the different instruments used, such as drill bits of different size and tap. By setting the tip of the instrument into a cup on the upper rim of the keyboard, the computer can determine its exact length. This is important if drill bits of different lengths are used and the progress of drilling, e.g. recognition of the drill bit passing the fracture line, has to be monitored.

CV. The clamp with a drill guide, described by WynJones, ${ }^{7}$ was used. Clamp position was adjusted side to side over the distal sesamoid bone based on fluoroscopic images (C-arm Siremobil Iso $C^{3 d}$, Siemens).

\section{Surgical Procedure}

CAS. Limb specimens were attached in an extended position, medial side down, to a radiolucent carbon board secured to the surgery table. The image intensifier, navigation computer, and camera were arranged so the surgeon's view of the navigation computer was not obstructed. The navigation camera was positioned so that it had an unobstructed view of the instruments, the $\mathrm{C}$-arm, and the DRB. Once this was achieved, the DRB was attached to the dorsal hoof wall by a specially designed Schanz screw. Fluoroscopic images (horizontal, sagittal, and transverse planes) of the distal sesamoid bone were acquired and transferred to the navigation computer, where brightness, contrast, and image size were adjusted. Screw position was then defined in the planning mode of the navigation system, so that the screw was positioned in the center of the distal sesamoid bone without penetrating the articular or flexor surfaces (Fig 2). Screw length was displayed on the computer screen.

The accuracy of the registration was checked in verification mode by pointing the awl to the 3 lead beads on the lateral hoof wall. After switching to guidance mode, the hoof wall entry point was localized and marked with an awl. Under computer guidance, a $10-\mathrm{mm}$ hole was drilled through the hoof wall and sensitive laminae to the distal phalanx and/or its collateral cartilage. The drill bit was changed to a $3.5-\mathrm{mm}$ diameter and calibrated on the virtual keyboard. The lateral collateral cartilage or the palmar eminence of the distal phalanx was penetrated and the glide hole advanced in the distal sesamoid bone until it just passed an imaginary midsagittal fracture line. Because it was not possible to create a controlled transverse fracture, an imaginary simple midsagittal fracture was assumed. Then, after insertion of a $2.5-\mathrm{mm}$ drill guide, a 2.5-mm diameter bit was used to complete the hole across the rest of the bone. A countersink was not used and after protecting the glide hole with a $3.5-\mathrm{mm}$ drill guide, threads were cut in the distal portion of the hole. Fluoroscopic images were acquired to obtain a $3 \mathrm{D}$ evaluation of the drill canal before screw insertion, because once inserted the screw scatters radiation, making interpretation impossible. ${ }^{12}$ Before screw insertion, the hole in the lateral collateral cartilage or lateral palmar eminence of the distal phalanx had to be enlarged to allow passage of the screw head. Then, a screw of predetermined length was inserted and solidly tightened with a screwdriver.

Time was recorded for each procedure, and untoward events were noted. Three standard radiographic projections (lateromedial, palmaroproximal-palmarodistal, dorsoproximal-palmarodistal oblique) of the distal sesamoid bone were obtained. $^{13}$

CV. Specimens were positioned and secured to the surgery table as described for CAS. The fluoroscope was centered in an exact lateromedial position relative to the distal sesamoid bone. The position of the drill-guiding device was adjusted after viewing fluoroscopic images so that it was aligned with the long axis of the distal sesamoid bone. Once correct alignment was ascertained, the guide was secured to the hoof by tightening the palmar and medial screw clamps (Fig 3). Before drilling, the $\mathrm{C}$-arm position was changed to obtain a dorsopalmar view of the distal sesamoid bone. An 8$\mathrm{mm}$ hole was drilled through the hoof wall, the sensitive laminae, and the lateral collateral cartilage or the palmar eminence of the distal phalanx to the distal sesamoid bone. A specially designed sleeve was inserted through the guide into the hole in the hoof wall to provide stability for the aiming system. A $2.5-\mathrm{mm}$ thread hole was drilled transversely through the distal sesamoid bone to its medial aspect. A flexible follower was used on this drill bit to determine screw length. 


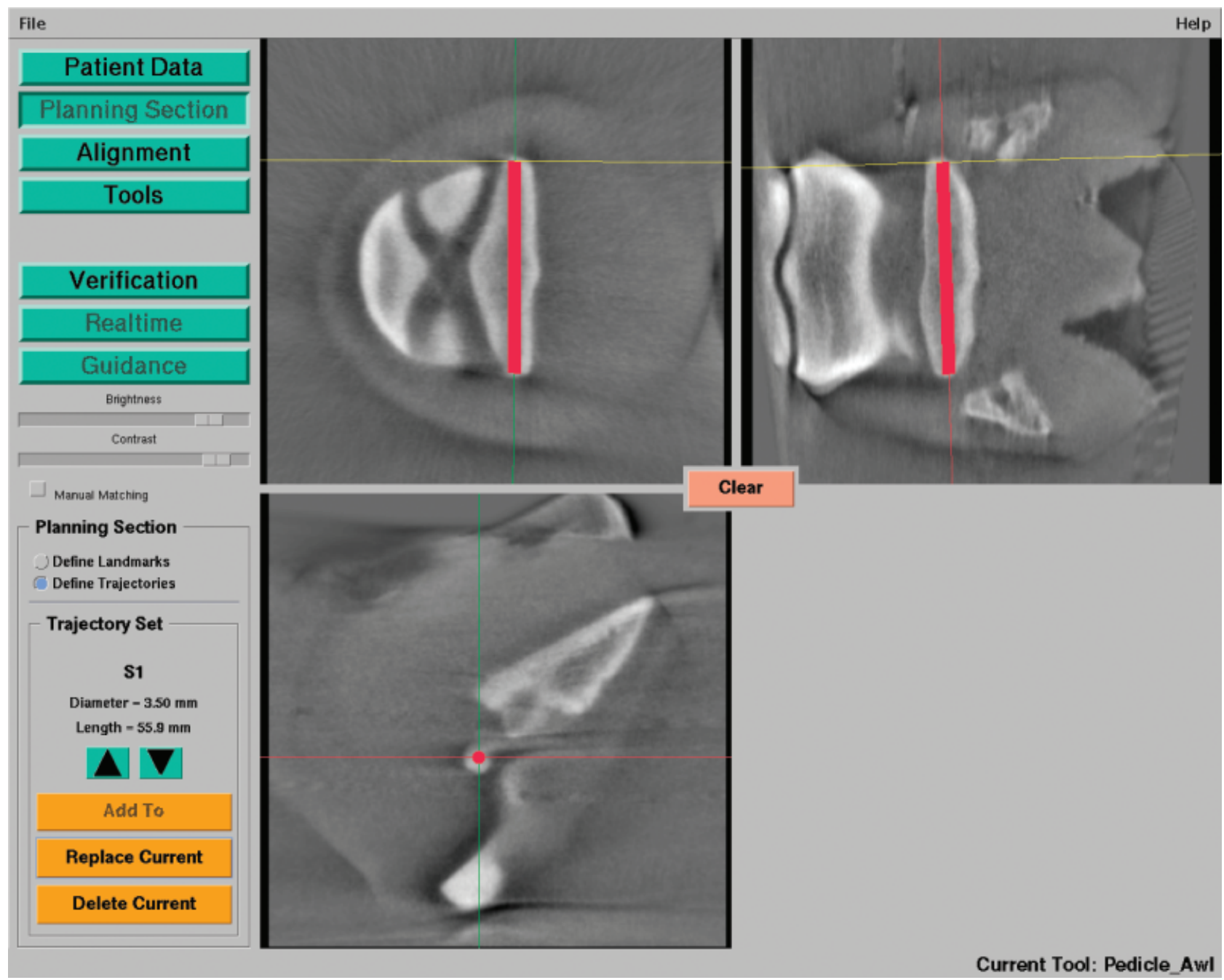

Fig 2. Screenshot made during the planning session. The distal sesamoid bone is projected in 3 different planes. The screw (red bar) is positioned in such a way as not to penetrate the bone surface.

Then, a 3.5-mm glide hole was drilled to the imaginary sagittal fracture line. The thread hole was tapped and fluoroscopic images were acquired as described for CAS. The screw was inserted, tightened, and radiographic projections of the distal sesamoid bone were taken as described for CAS.

\section{Evaluation}

The accuracy of screw placement was determined by evaluation of pre and postoperative fluoroscopic images without the screw, postoperative radiographs with the screw inserted, and on gross inspection of dissected distal sesamoid bones. Gross inspection of the distal sesamoid bone was considered the gold standard for evaluation of screw placement.

Fluoroscopic Images. The hole inside the distal sesamoid bone was examined in 3 planes. The drill hole was considered perfect, if the canal was within the long axis of the distal sesamoid bone without touching the articular and flexor surfaces, and the distal and proximal rim of the bone. It was defined as moderate if the canal contacted one of these 4 surfaces and as poor if the canal protruded through any of the 4 surfaces.

Radiographs. A radiologist (D.N.) unaware of the surgical method used in each specimen examined all radiographic projections. Four criteria were assessed and scored separately: screw length $(1=$ adequate, $2=$ too long, $3=$ too short $)$, screw head position $(1=$ well positioned, $2=$ too much inserted, $3=$ protruding), screw condition $(1=$ straight, $2=$ bent $)$, and screw position within the distal sesamoid bone $(1=$ touching the proximal margin of distal sesamoid bone, 2 = touching the distal margin of distal sesamoid, $3=$ touching the articular surface, $4=$ touching the flexor surface). Outcome was determined by summation of scores: perfect (score 3), moderate (score 4-8), and poor (score 9-12 or if the position of the screw was scored 2-4).

Gross Evaluation. Removal of the horn capsule from the corium was facilitated by heating the hooves for 1 hour in water at $65^{\circ} .{ }^{14}$ Subsequently, the distal sesamoid bone was 


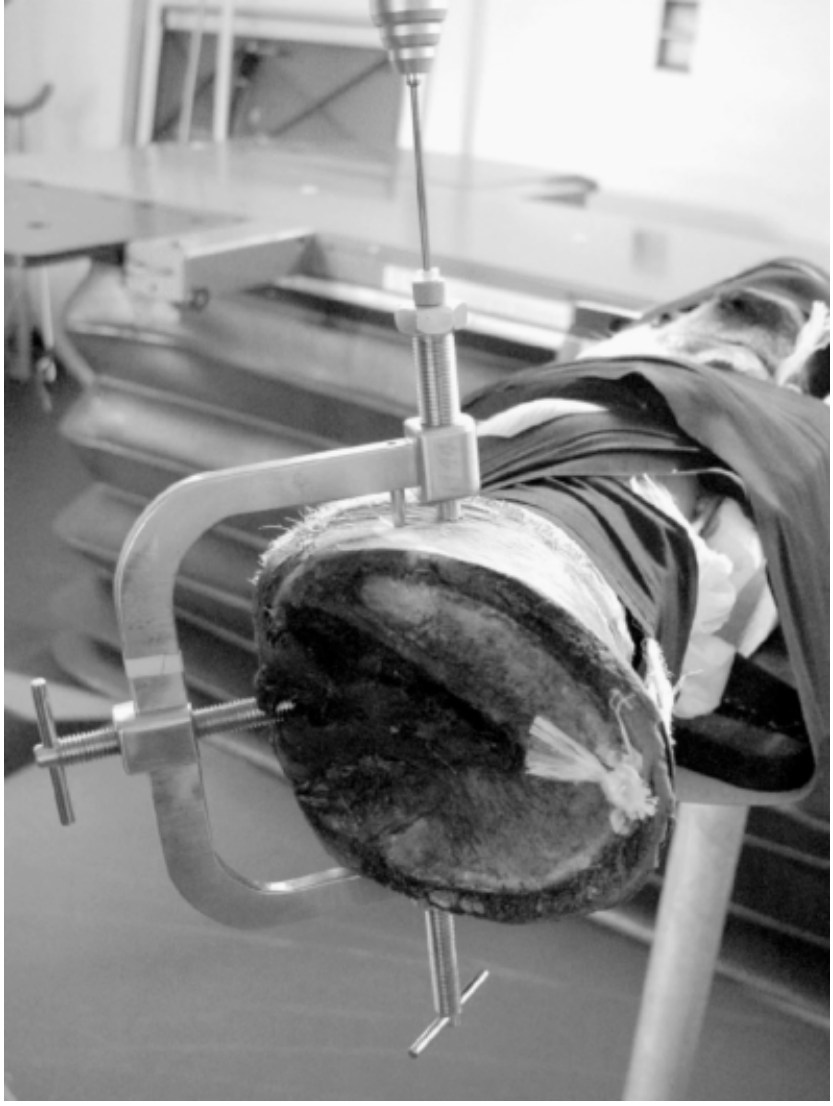

Fig 3. Guiding device attached to the hoof during the drilling process.

bluntly dissected from the remainder of the specimen and its length was measured. The articular and flexor surfaces, the proximal and distal rims, and the medial and lateral ends of the distal sesamoid bone were closely inspected. Outcome related to screw position was determined by whether or not the screw was visible: perfect outcome $=$ no visible screw; moderate outcome $=$ screw resulted in slight bulging of the bone surface; and poor outcome $=$ when the screw was causing damage to the surface or was protruding (Fig 4). The same criteria and scoring system used for radiographic evaluation were used. The position of the screw head relative to the bone surface was checked.

\section{Statistical Analyses}

Collected data were statistically analyzed using Student's ttest to evaluate differences in size of the distal sesamoid bone between groups. Fisher-corrected $\chi^{2}$-test was used for differences in outcome between groups. The expressiveness of fluoroscopic images and radiographs with regard to outcome was analyzed by using a frequencies of agreement test and a Cohen's unweighted $\kappa$ test. All analyses were performed using commercial computer software (SPSS). For all analyses, a $P$ value $<.05$ was considered significant.

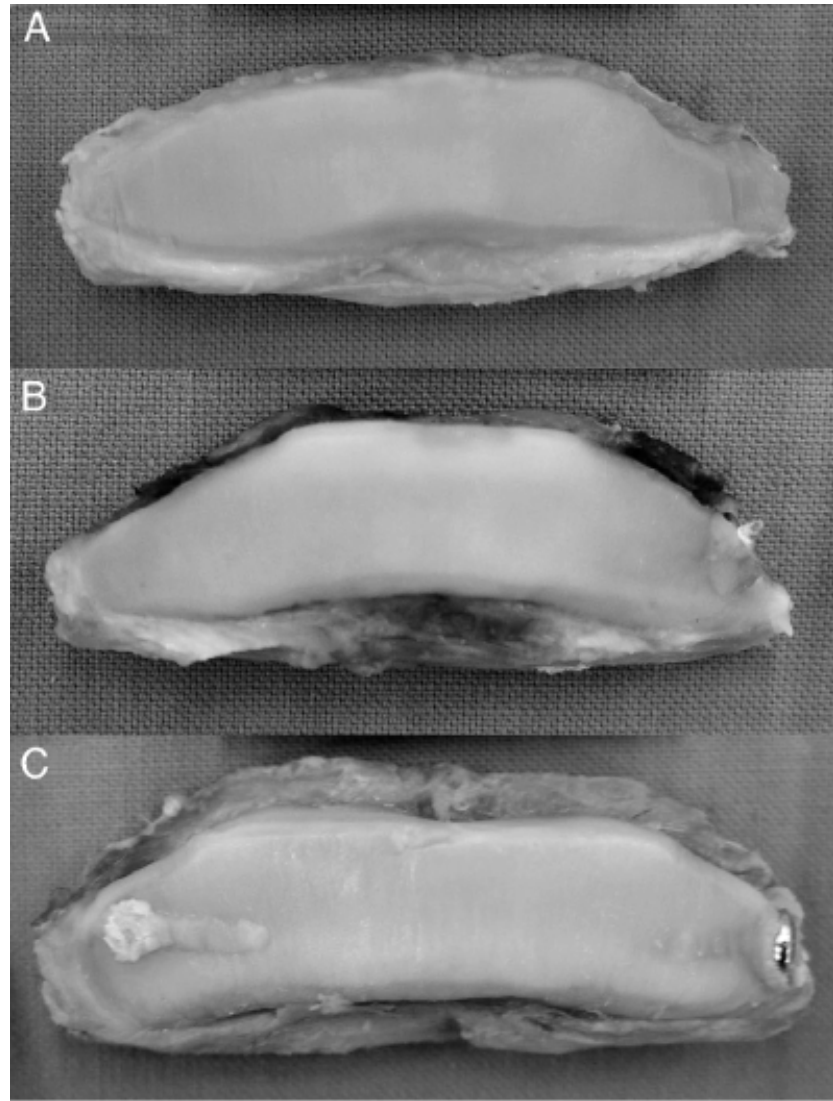

Fig 4. Three different distal sesamoid bones after dissection: (A) example of a perfect outcome; (B) moderate outcome with bulging of the cartilage on the articular surface; $(C)$ poor outcome with cartilage damage on the articular surface.

\section{RESULTS}

The length (CV: $54.95 \pm 5.02 \mathrm{~mm}$; CAS: $55.91 \pm$ $4.12 \mathrm{~mm})$ and the width in the midline $(\mathrm{CV}: 15.30 \pm$ $1.23 \mathrm{~mm}$; CAS: $15.76 \pm 1.50 \mathrm{~mm}$ ) of the distal sesamoid bone did not differ between groups.

There was no significant difference in surgical time: CV 27 minutes 36 seconds \pm 4 minutes 20 seconds and CAS $27 \pm 5$ minutes 16 seconds. The most challenging and time-consuming part of the $\mathrm{CV}$ procedure was positioning the guiding device so that it was aligned perfectly with the long axis of the distal sesamoid bone. The mean time for this step was 7 minutes 51 seconds, which was one-third of the surgical time. Once tightly fixed onto the hoof wall, the device was not displaced in any of the 8 limbs. In the CAS group, the transfer of the acquired imaging data from the $\mathrm{C}$-arm to the navigation computer failed in 1 specimen, so the procedure had to be repeated. The time used for planning the screw position on the computer screen varied considerably ( 2 minutes 29 seconds to 7 minutes 30 seconds). Screenshots of 
Table 1. Time for Surgical Procedure, Results of Dissection and Outcome of Surgery for the 16 Distal Sesamoid Bones

\begin{tabular}{|c|c|c|c|c|c|c|c|}
\hline \multirow[b]{3}{*}{ Case No. } & \multirow[b]{3}{*}{ Time (Minutes, Seconds) } & \multicolumn{5}{|c|}{ Results of Dissection } & \multirow[b]{3}{*}{ Outcome } \\
\hline & & \multicolumn{4}{|c|}{ Damage to Surface of Navicular Bone } & \multirow[b]{2}{*}{ Screw Head } & \\
\hline & & Articular & Flexor & Distal Rim & Proximal Rim & & \\
\hline $\mathrm{CV} 2$ & $28 \mathrm{~m} \mathrm{13} \mathrm{s}$ & + & - & ++ & - & OK & Poor \\
\hline $\mathrm{CV} 3$ & $24 \mathrm{~m} 56 \mathrm{~s}$ & - & - & + & - & OK & Moderate \\
\hline $\mathrm{CV} 4$ & $25 \mathrm{~m} 42 \mathrm{~s}$ & - & - & ++ & - & $\mathrm{OK}$ & Poor \\
\hline CV 7 & $25 \mathrm{~m} 20 \mathrm{~s}$ & - & - & - & - & OK & Perfect \\
\hline $\mathrm{CV} 8$ & $23 \mathrm{~m} 27 \mathrm{~s}$ & - & - & - & - & OK & Perfect \\
\hline CAS 1 & $36 \mathrm{~m} 41 \mathrm{~s}$ & - & - & - & - & $\mathrm{OK}$ & Perfect \\
\hline CAS 2 & $30 \mathrm{~m} 36 \mathrm{~s}$ & - & - & - & - & Too deep & Moderate \\
\hline CAS 3 & $24 \mathrm{~m} 58 \mathrm{~s}$ & + & - & - & - & $\mathrm{OK}$ & Moderate \\
\hline CAS 4 & $27 \mathrm{~m} 22 \mathrm{~s}$ & - & - & + & - & Too deep & Moderate \\
\hline
\end{tabular}

+ , slightly affected by the screw (bulging of the cartilage or the bone surface); ++ , plainly affected by the screw (damage of the cartilage or the bone surface, screw is visible); - , not affected by the screw; CV, conventional; CAS, computer-assisted surgery.

the Planning Section (Fig 2) were judged once more after the event. In all 8 specimens, the planned screw did not affect the bone surface. In verification mode, the accuracy of registration was considered very good in all 8 cases. Drilling of the screw hole was continuously checked on the monitor and required considerable concentration and good hand-eye coordination by the surgeon.

\section{Screw Position}

Perfect screw position within the distal sesamoid bone was achieved in 4 CAS specimens and $2 \mathrm{CV}$ specimens (Table 1). Screw position was considered moderate in 3 specimens of each group and poor 1 CAS specimen and $3 \mathrm{CV}$ specimens. The distal rim of the distal sesamoid bone was more affected in the $\mathrm{CV}$ group (5 specimens) than in the CAS group (1 specimen). The articular surface was affected in 3 (CV 1; CAS 2). In neither group did the screw interfere with the proximal rim or the flexor surface. Protrusion of the screw head was observed in $1 \mathrm{CV}$ specimen and overinsertion of the screw in 2 CAS specimens. No significant difference in outcome was detected between groups.

Radiographic evaluation was very useful for discriminating between poor and moderate or perfect outcome but was not useful for differentiating between perfect and moderate positioning. C-arm scans were very accurate in identifying perfect and poor screw position but not useful for detection of moderate screw position (Table 2).

\section{DISCUSSION}

Compared with a conventional screw insertion technique, computer-assisted screw insertion was more precise for positioning a $3.5-\mathrm{mm}$ screw in lag fashion within the distal sesamoid bone. With the CV, screw insertion into the distal sesamoid bone for fracture repair requires repeated radiographs or an image-intensifying system ${ }^{7,15}$; in our experience, a C-arm was essential to accomplish the procedure.

\section{CV}

With CV, the first but crucial step is to position the image intensifier so that an exact lateromedial view of the distal sesamoid bone is obtained. We found that to find the correct position for the guiding aiming device, at least 20 projections had to be made with the image intensifier. Also, we found that it was easy to lose alignment while securing the guiding device to the hoof wall by tightening the caudal and medial screw clamps. It became apparent that it was very helpful for an assistant to hold the guiding device while the surgeon tightened the clamps. Once securely tightened onto the hoof, the clamp provided secure guidance of drill bits. Several radiographs (dorsopalmar projection) were needed to follow the drilling process closely and to determine the correct screw length. Because the sequence of drilling and tapping was carried out under fluoroscopic control, the surgeon could avoid the risk of overdrilling or overtapping. In the presence of a C-arm and with some practical experience in 
Table 2. Evaluation of the 16 Distal Sesamoid Bones Based on the Information Gained from the C-Arm Data, the X-Rays and the Dissection

\begin{tabular}{llll}
\hline Case No. & C-Arm & X-Ray & Dissection \\
\hline CV 1 & Moderate & Poor & Poor \\
CV 2 & Moderate & Poor & Poor \\
CV 3 & Moderate & Moderate & Moderate \\
CV 4 & Moderate & Moderate & Poor \\
CV 5 & Poor & Poor & Moderate \\
CV 6 & Moderate & Moderate & Moderate \\
CV 7 & Perfect & Moderate & Perfect \\
CV 8 & Moderate & Moderate & Perfect \\
CAS 1 & Perfect & Moderate & Perfect \\
CAS 2 & Perfect & Moderate \\
CAS 3 & Poor & Moderate & Moderate \\
CAS 4 & Perfect & Moderate \\
CAS 5 & Perfect & Moderate \\
CAS 6 & Perfect & Poor & Moderate \\
CAS 7 & Poor & Moderate \\
CAS 8 & Perfect & Poderate \\
\hline
\end{tabular}

$\mathrm{CV}$, conventional; CAS, computer-assisted surgery.

application of the aiming device, the $\mathrm{CV}$ technique could be performed relatively easily.

\section{$C A S$}

CAS is a new technique for facilitating screw insertion into the distal sesamoid bone. Because the DRB could not be attached to the distal sesamoid bone itself, it was inserted into the dorsal hoof wall, which proved to be a valuable alternative. From our perspective, it is important to fix the distal limb in an extended position to stabilize the distal sesamoid bone between a taut deep flexor tendon and the distal/middle phalanx to minimize movement of the distal sesamoid bone relative to the DRB. Inadvertent displacement of the distal sesamoid bone, relative to the DRB caused by an instrument, would not be registered by the computer and would therefore mislead the surgeon's understanding of the actual drill bit and screw alignment leading to penetration of a cortex.

For image acquisition, it was absolutely critical that the central beam of the $\mathrm{C}$-arm was centered exactly on the distal sesamoid bone to achieve the highest accuracy possible. During image acquisition, personnel can remain outside the operating room, which reduces radiation exposure considerably compared with the $\mathrm{CV}$ technique. On the 3 orthogonal views, depicted on the computer screen during the planning mode, it was obvious that the shape of the distal sesamoid bones had great variability. Distal sesamoid bones with a curved form were very difficult to deal with, which resulted in a prolonged planning time for ideal screw position. These shape details could not be detected on 2D projections used with the $\mathrm{CV}$ technique.
The lead beads mounted on the lateral hoof wall were of great value for checking the accuracy of registration in verification mode because of their ready identification and because of the lack of other usable anatomic landmarks on the hoof wall. The beads had to be small enough to avoid creation of artifacts, but large enough to be recognized clearly on the image. After penetrating the hoof wall and the sensitive laminae, the $10-\mathrm{mm}$ drill bit was exchanged for a $3.5-\mathrm{mm}$ bit because the $10-\mathrm{mm}$ bit would cause excessive damage to the collateral ligaments of the distal sesamoid bone and secondly the glide hole across the lateral collateral cartilage (or the palmar eminence of the distal phalanx) guides the drill bit preventing the drill bit from slipping off the rather roundly shaped lateral surface of the distal sesamoid bone.

When using a long drill bit, the surgeon has to pay attention not to bend it while concentrating on the computer screen. The LED, which are identified by the optoelectronic infrared camera, are attached to the power drill and not to the drill bit itself. If the surgeon is moving the drill during the drilling process to line it up in the correct position on the virtual screen, the computer screen shows a change of drilling direction, but in fact, once the drill bit has penetrated the bone its direction is fixed and the surgeon is just bending the drill without actually changing the drill bit position. It is consequently of utmost importance for screw insertion in the correct location to position the drill bit very accurately at the beginning of the drilling process and to prevent any unnecessary adjustment of the drill bit. When working with the CAS system, it is critical to define precisely the implantation protocol and follow it exactly to minimize technical failures and improve clinical outcome. 


\section{Imaging}

With radiography, we were able to differentiate between a poor outcome and a moderate or perfect outcome but not between moderately and perfectly implanted screws. Use of C-arm scanning allowed identification of perfect and poor outcomes but not moderate ones. Images obtained from radiography or C-arm scanning permitted reliable detection of a poor outcome. A poor outcome can be equated clinically with failure of the surgical procedure and a perfect or moderate outcome with successful surgery. Thus, radiography and 3D imaging are both valuable diagnostic tools to determine surgical technique outcome. A disadvantage of the C-arm scanning is that it was not possible to obtain images of the distal sesamoid bone with the screw inserted and knowing whether the screw was bent or how far it had been inserted could not be ascertained.

In these specimens, we found that CAS was a useful alternative to conventional surgical techniques for repair of distal sesamoid bone fractures. More experience with clinical cases are needed to assess its actual value.

\section{REFERENCES}

1. Stashak TS: The foot, in Stashak TS (ed): Adams' Lameness in Horses (ed 5). Philadelphia, PA, Lea \& Febiger, 2002, pp 645-733

2. Rick MC: Navicular bone fractures, in White NA, Moore JN (eds): Current Practice of Equine Surgery. Philadelphia, PA, Lippincott, 1990, pp 602-605

3. Fürst A, Lischer C: The foot, in Auer JA, Stick JA (eds): Equine Surgery (ed 3). Philadelphia, PA, Saunders, 2006, pp 1184-1217
4. Lillich JD, Ruggles AJ, Gabel AA: Fracture of the distal sesamoid bone: 17 cases (1982-1992). J Am Vet Med Assoc 207:924-927, 1995

5. Reeves MJ: Miscellaneous conditions of the equine foot. Vet Clin North Am 5:602-605, 1989

6. Nemeth F, Dik KJ: Lag screw fixation of sagittal navicular bone fractures in five horses. Equine Vet J 17:137-139, 1985

7. Wyn-Jones G: Fractures of the equine navicular bone. Vet Ann 25:201-210, 1985

8. Lain T, Lund T, Ylikoski M, et al: Accuracy of pedicle screw insertion with and without computer assistance: a randomized controlled clinical study in 100 consecutive patients. Eur Spine J 9:35-40, 2000

9. Gautier E, Baechler R, Heini PF, et al: Accuracy of computer-guided screw fixation of the sacroiliac joint. Clin Orthop 393:310-317, 2001

10. Caversaccio M, Nolte LP, Haeusler R: Present sate and future perspectives of computer aided surgery in the field of ENT and skull base. Acta Otorhinolaryngol Belg 56:51-59, 2002

11. Andritzky J, Rossol M, Lischer C, et al: Comparison of computer-assisted surgery with conventional technique for the treatment of axial distal phalanx fractures in horses: an in vitro study. Vet Surg 34:120-127, 2005

12. Curry TS, Dowdey JE, Murry RC: Computed tomography, in Christensen S (ed): Physics of Diagnostic Radiology (ed 4). Philadelphia, PA, Lippincott, 1990, pp 289-322

13. Butler JA, Colles CM, Dyson SJ, et al: Clinical Radiology of the Horse. Oxford, UK Blackwell Science, 2000, pp 57-63

14. Ossent P: Post mortem examination of the hooves of cattle, horses, pigs and small ruminants under practice conditions. In Practice 19:21-28, 1997

15. Colles CM: How to repair Navicular Bone Fractures in the Horse. Proc Am Assoc Equine Practnr 47:270-278, 2001 


\section{$\underline{\text { Lebenslauf }}$}

\section{Personalien}

Name: Gygax

Vorname: Diego Andreas

Wohnort: Mühleweg 61

4813 Uerkheim

Geburtsdatum: 29.09.1973

Heimatort: Reitnau

\section{Ausbildung}

1980-1985: Primarschule in Brittnau

1985-1990: Bezirksschule in Brittnau

1990-1994: Kantonsschule in Zofingen, Typus D

1995-2002: Veterinärmedizinisches Studium an der Universität Bern

\section{Berufliche Tätigkeiten}

Februar 2002: Externship im Beaufort Cottage Equine Hospital in Newmarket 2003: Internship auf der Chirurgischen Abteilung der Pferdeklinik der Universität Zürich 2003-2006: Residency auf der Chirurgischen Abteilung der Pferdeklinik der Universität Zürich 